\title{
ADHD Awareness Among Medical Students
}

\author{
Hebah F Qashqari, Abdulaziz O Alsulami, Eman K Kamal, Mohammed M.S. Jan
}

\begin{abstract}
Background: Early recognition of attention deficit hyperactivity disorder (ADHD) is needed to prevent its psychosocial and educational consequences. We aimed to study ADHD awareness among medical students and identify correlating and contributing factors to their lack of knowledge. Methods: A cross sectional study included 5th year medical students attending their pediatric rotation from September 15, 2012 until June 15, 2013 at King Abdulaziz University hospital, Jeddah, Kingdom of Saudi Arabia. A structured 25-item questionnaire was designed to examine their demographics , educational experience, and awareness questions about ADHD. Results: Of 120 approached students, 111 were included with ages ranging from 20-29 years (mean 22) and 69\% being females. Most students $69(62 \%)$ were enrolled during their pediatric rotation and $97(87 \%)$ already completed their psychiatry course. Although most students $(67 \%)$ recognized ADHD, only $13(12 \%)$ categorized their level of knowledge as very good or excellent. Only $\mathbf{2 4 \%}$ correctly recognized ADHD subtypes and $58 \%$ did not know what is the initial required management step. Only 19 students (17\%) correctly recognized all ADHD features based on the DSM IV criteria with a mean correct score of $69 \%$ (standard deviation 14). No correlations were found with their age, gender, completing their pediatric/ psychiatry rotation, or specialty interests.

Conclusions: Medical student's level of knowledge about ADHD needs improvement. This has to be corrected in order to improve early recognition and intervention. Increased ADHD education and exposure during pediatric/neuroscience modules are needed in our region.
\end{abstract}

Index Terms - ADHD, awareness, knowledge, medical, students.

\section{INTRODUCTION}

Attention deficit hyperactivity disorder (ADHD) is a neuro-behavioral disorder that impairs social, academic and occupational functions [1]-[3]. It is sub-classified as inattentive, hyperactivity, or combined type [4]. The prevalence of ADHD worldwide is highly variable, ranging from 1-20\% among school-age children [5]. A recent Saudi study revealed a prevalence of $11.6 \%$ among elementary school children in the city of Jeddah [6].

Community physicians and general practitioners are expected to recognize ADHD in order to promptly initiate appropriate diagnostic and therapeutic interventions [7].

Hebah F Qashqari, Department of Pediatric, King Abdulaziz University/ Faculty of Medicine, Jeddah, Kingdom of Saudi Arabia

Abdulaziz O. Alsulami, Department of Pediatric, King Abdulaziz University/ Faculty of Medicine, Jeddah, Kingdom of Saudi Arabia,

Eman Kmal Kmal, Department of Pediatric, King Abdulaziz University/ Faculty of Medicine, Jeddah, Kingdom of Saudi Arabia

Mohammed M. S. Jan, Department of Pediatric, King Abdulaziz University/ Faculty of Medicine, Jeddah, Kingdom of Saudi Arabia
Such early intervention and referrals are needed to prevent the psychosocial and educational consequences of $\mathrm{ADHD}$ on the child and family [8].

Our objectives were to study ADHD awareness among medical students and identify correlating and contributing factors to their lack of knowledge. These may include personal and educational exposure and experiences. This area has received limited study in our region. We hypothesize that many medical students are not aware about the features of ADHD adding to the problem of early detection and underestimation of this problem in our region.

\section{METHODS}

A cross sectional study included 5th year medical students attending their pediatric rotation from September 15, 2012 until June 15, 2013 at the faculty of medicine, King Abdulaziz University, Jeddah, Kingdom of Saudi Arabia. The Faculty of medicine at King Abdulaziz University is the largest in the western region of Saudi Arabia accepting up to 200 medical students annually. Students were enrolled randomly during their teaching sessions by the first author. A structured 25-item questionnaire was designed to examine their demographics, educational experience, and specialty interests. Specific awareness questions about ADHD were included to examine their knowledge about the disorder (table I). A final item was included to identify specific ADHD features based on the DSM IV criteria to verify their understanding of the disorder (table II). The questionnaires were distributed and then completed in the presence of a research member to assist the students and then collected immediately to avoid consultation or discussion of the study material. The study design and questionnaire were approved by King Abdulaziz University hospital ethics committee. All included students consented voluntarily to the study.

Data were collected in Excel sheets and statistical analysis was performed using SPSS 17 (SPSS, Inc., Chicago, IL, USA). Descriptive analyses were performed and the variables were examined using chi-square test. Statistical significance will be defined as $\mathrm{P}$ values of less than 0.05 .

\section{RESULTS}

One hundred and twenty (out of 320) 5th year medical students were randomly recruited to complete the study questionnaire. Only 3 of the approached students declined to participate. However, 9 forms were incomplete and therefore excluded. Student's ages ranged from 20-29 years (mean 22.3 , Standard deviation 1.03) with $69 \%$ being females. Only 5 students (all females) were married and 3 of them already 
Table I: Summary of student's responses to specific ADHD awareness questions.

\begin{tabular}{|c|c|}
\hline ADHD Features & $\begin{array}{c}\text { Correct Answers } \\
\text { Number / total* } \\
\text { (percentage) }\end{array}$ \\
\hline \multicolumn{2}{|l|}{ Diagnosis: } \\
\hline Any child with difficulty in paying attention should be diagnosed with ADHD? & $101 / 107(94 \%)$ \\
\hline Should the diagnosis be based on the parents and/or teacher's input? & 97 / $109(89 \%)$ \\
\hline ADHD can be diagnosed by a blood test? & $91 / 104(87 \%)$ \\
\hline $\begin{array}{l}\text { What is the duration of symptoms required before a given child could be labeled as } \\
\text { having ADHD? }\end{array}$ & $61 / 98(62 \%)$ \\
\hline Other psychiatric or neurologic diseases must accompany ADHD? & $65 / 109(60 \%)$ \\
\hline ADHD is sub-classified into how many subtypes? & $21 / 87(24 \%)$ \\
\hline \multicolumn{2}{|l|}{ Management: } \\
\hline Does ADHD affect the child's school performance? & $107 / 111(96 \%)$ \\
\hline What is the best management approach for treating children with ADHD? & $95 / 111(86 \%)$ \\
\hline A child with ADHD should be placed in a special school? & $69 / 110(63 \%)$ \\
\hline Children with ADHD are cured by treatment? & $46 / 106(43 \%)$ \\
\hline What is the initial step when ADHD is suspected? & $45 / 107(42 \%)$ \\
\hline
\end{tabular}

*Total number of students who answered the question.

had children. Fifteen students $(13 \%)$ had a positive family history of neuro-behavioral disorders (ADHD in 6 cases).

Regarding their educational backgrounds and experiences, 69 students (62\%) were enrolled during their pediatric rotation and $97(87 \%)$ already completed their psychiatry course. Regarding their specialty interests, 17 students (15\%) preferred pediatrics and $14(13 \%)$ were interested in the neuroscience field. When asked if they know what ADHD abbreviation stands for, $75(67 \%)$ students responded positively. However, when these students were asked to spell out the exact meaning of the words, only $62 \%$ of them did it correctly. As well, only $13(11 \%)$ categorized their level of knowledge about ADHD as very good or excellent (fig. I).

Table 1 summarizes student's responses to specific ADHD awareness questions. No positive correlations were found with age, gender, completing their pediatric/ psychiatry rotation, or specialty interests. Student's answers to the specific ADHD features based on the DSM IV criteria are summarized in table 2 . Only 19 students $(17 \%)$ recognized all 11 ADHD features correctly with a mean correct score of 69\% (standard deviation 14). Again, the score did not correlate positively with age, gender, completing their pediatric/ psychiatry rotation, or specialty interests.

\section{DISCUSSION}

Our study documented that medical students are not well educated about ADHD features, diagnosis, and management. They had significant deficiencies in their knowledge, which was reflected on their perceived confidence in the level of their information. This was confirmed by using more specific questions on ADHD symptomatology, diagnostic criteria, and management guidelines (table I\&II). These findings are problematic given that the students will soon graduate and have their eneral practice where they are expected to promptly recognize ADHD and initiate appropriate management plans. This is particularly important given that ADHD is a very common outpatient clinic problem [9]. As well, earlier diagnosis and management of ADHD would affect the future outcome of affected children [10]. Graduate physicians are often faced with anxious parents and therefore have a great responsibility and can have an important role in screening, diagnosis, and management of ADHD. Several studies have documented lack of knowledge regarding ADHD among general practitioners and in many countries worldwide such knowledge should be improved [11]-[14]. This is likely the result of inadequate training during their 
medical education [15]-[17]. Our study adds to this body of literature and calls for improved exposure and education about ADHD in undergraduate student curricula. This is more critical in our region because of the limited numbers of child psychiatrists, developmental pediatricians, and child neurologists [18],[19].

There are some limitations to our study. We were not able to find any correlations between the student's level of knowledge and their age, gender, or academic experience or interests. This finding may be true and general but it is possible that the lack of significant association is related to our relatively small study sample. It may be also related to the limited exposure and experience of the involved medical students. One would expect that students with interest in the pediatric or neuroscience fields to be more informed about ADHD. Our study could also be affected by reporting bias. We tried to overcome this by assigning one coauthor to personally assist all students in completing the questionnaire.

\section{CONCLUSION}

We conclude that the level of knowledge of medical student's about ADHD needs improvement. This has to be corrected in order to improve early recognition and intervention. Increased ADHD education and exposure during pediatric/neuroscience modules are needed in our region. More emphasis is required on ADHD screening using structured diagnostic tools for early recognition and initiation of the required interventions. Post-graduate ADHD educational programs should be developed targeting fresh medical graduates.

Table II: Specific ADHD features to verify student's understanding of the disorder based on the DSM IV criteria $(\mathbf{n}=111)$.

\begin{tabular}{|l|c|}
\hline $\begin{array}{l}\text { The following features apply to the } \\
\text { child with ADHD }\end{array}$ & $\begin{array}{c}\text { Yes Answers } \\
\text { Number } \\
\text { (percentage) }\end{array}$ \\
\hline $\begin{array}{l}\text { Has difficulty sustaining attention to } \\
\text { task }\end{array}$ & $102(91 \%)$ \\
\hline $\begin{array}{l}\text { Often run or climbs in situation where } \\
\text { it is inappropriate }\end{array}$ & $92(83 \%)$ \\
\hline $\begin{array}{l}\text { Often easily distracted by external } \\
\text { stimuli }\end{array}$ & $92(83 \%)$ \\
\hline Often has difficulty waiting turn & $91(82 \%)$ \\
\hline $\begin{array}{l}\text { Fails to give attention to details or } \\
\text { make careless mistakes }\end{array}$ & $90(81 \%)$ \\
\hline $\begin{array}{l}\text { Not seems to listen when spoken to } \\
\text { directly }\end{array}$ & $83(75 \%)$ \\
\hline Often act as driven by motor & $80(72 \%)$ \\
\hline $\begin{array}{l}\text { Often have difficulty organizing task or } \\
\text { activity }\end{array}$ & $79(72 \%)$ \\
\hline $\begin{array}{l}\text { Often answer before question } \\
\text { completed }\end{array}$ & $78(71 \%)$ \\
\hline Often talk excessively & $75(67 \%)$ \\
\hline Often forgetful in daily activities & $64(57 \%)$ \\
\hline
\end{tabular}

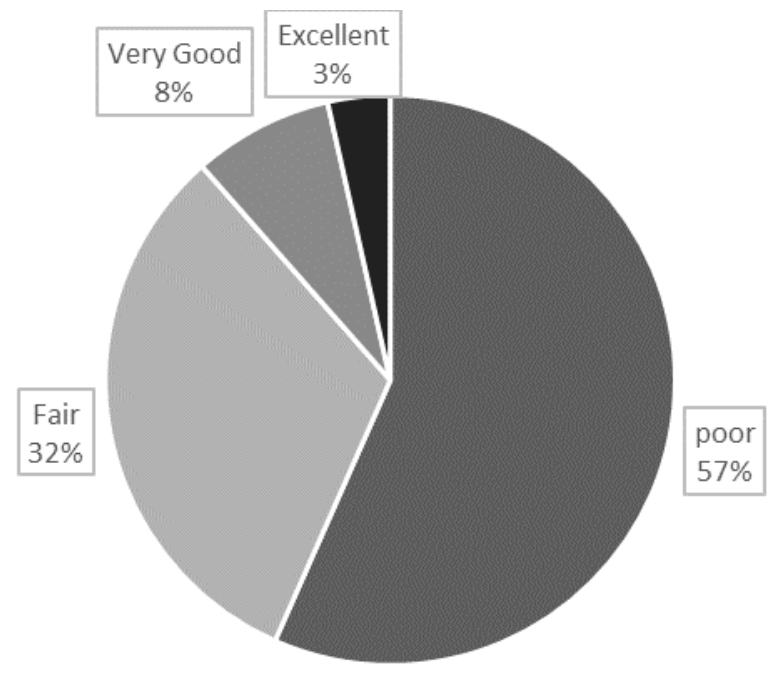

Figure I: How do you categorize your level of knowledge about ADHD.

\section{REFERENCES}

[1] Storebo OJ, Skoog M, Damm D, Thomsen PH, Simonsen E, Gluud C. Social skills training for Attention Deficit Hyperactivity Disorder (ADHD) in children aged 5 to 18 years. Cochrane Database Syst Rev 2011;(12):CD008223.

[2] Shaw K, Wagner I, Eastwood H, Mitchell G. A qualitative study of Australian GPs' attitudes and practices in the diagnosis and management of attention-deficit/hyperactivity disorder (ADHD). Fam Pract 2003;20(2):129-34

[3] Ougrin D, Chatterton S, Banarsee R. Attention deficit hyperactivity disorder (ADHD): review for primary care clinicians. London J Prim Care 2010;3(1):45-51.

[4] Sciberras E, Efron D, Schilpzand EJ, Anderson V, Jongeling B, Hazell P, Ukoumunne OC, Nicholson JM. The children's attention project: a community-based longitudinal study of children with ADHD and non-ADHD controls. BMC Psychiatry 2013;10(13):18.

[5] Polanczyk G, de Lima MS, Horta BL, Biederman J, Rohde LA. The worldwide prevalence of ADHD: a systematic review and metaregression analysis. Am J Psychiatry. 2007 Jun;164(6):942-8.

[6] Homidi M, Obaidat Y, Hamaidi D. Prevalence of attention deficit and hyperactivity disorder among primary school students in Jeddah city, KSA. Life Sci J 2013;10(3):280-5.

[7] Leslie LK, Weckerly J, Plemmons D, Landsverk J, Eastman S Implementing the american academy of pediatrics attention-deficit/hyperactivity disorder diagnostic guidelines in primary care settings. Pediatrics. 2004 Jul;114(1):129-40.

[8] Subcommittee on Attention-Deficit/Hyperactivity Disorder; Steering Committee on Quality Improvement and Management, Wolraich M, Brown L, Brown RT, DuPaul G, Earls M, Feldman HM, Ganiats TG, Kaplanek B, Meyer B, Perrin J, Pierce K, Reiff M, Stein MT, Visser S. ADHD: clinical practice guideline for the diagnosis, evaluation, and treatment of attention-deficit/hyperactivity disorder in children and adolescents. Pediatrics 2011;128(5):1007-22.

[9] Al-Haidar FA. Co-morbidity and treatment of attention deficit hyperactivity disorder in Saudi Arabia. East Mediterr Health J 2003;9(5):988-95

[10] Foy JM, Earls MF. A process for developing community consensus regarding the diagnosis and management of attention-deficit/hyperactivity disorder. Pediatrics 2005;115(1):e97-104.

[11] Zaki RA. Enhancement the awareness of family care givers caring their children with attention deficit hyperactivity disorder of the general administration of intellectual education centers in the city of Abha. J Am Sci 2013;9(8):46-53.

[12] Jawaid A1, Zafar AM, Naveed A, Sheikh S, Waheed S, Zafar MA, Syed EU, Fatmi Z. Knowledge of primary paediatric care providers regarding attention deficit hyperactivity disorder and learning disorder: a study from Pakistan. Singapore Med J. 2008;49(12):985-93.

[13] Ghanizadeh A1, Zarei N. Are GPs adequately equipped with the knowledge for educating and counseling of families with ADHD children? BMC Fam Pract 2010;21(11):5-11. 
[14] Thapar A, Thapar A. Is primary care ready to take on Attention Deficit Hyperactivity Disorder? BMC Fam Pract 2002;3:7.

[15] Jawaid A, Zafar AM, Naveed A, Sheikh S, Waheed S, Zafar MA, Syed EU, Fatmi Z. Knowledge of primary paediatric care providers regarding attention deficit hyperactivity disorder and learning disorder: a study from Pakistan. Singapore Med J 2008;49(12):985-93.

[16] Phillips A, Morrison J, Davis RW. General practitioners' educational needs in intellectual disability health. J Intellect Disabil Res 2004;48(Pt 2): $142-9$.

[17] Lian WB, Ho SK, Yeo CL, Ho LY. General practitioners' knowledge on childhood developmental and behavioural disorders. Singapore Med J 2003;44(8):397-403.

[18] Jan MM. Pediatric neuro-developmental and behavioral disorders: practitioner's perspectives. Neurosciences 2005;10(2):149-54.

[19] Jan MM. Pediatric neurologists in saudi arabia: an audit of current practice. J Pediatr Neurol 2005;3(3):131-6.

Hebah F Qashqari, Pediatric Resident, MD, King Abdul-Aziz University, Jeddah, Saudi Arabia.

Abdulaziz O Alsulami, Medical Intern, Degree of Bachelor in Medicine \& Surgery, King Abdulaziz University, Jeddah, Saudi Arabia.

Eman K Kamal, Medical intern, Medicine and Surgery bachelor degree, King Abdul-Aziz University, Jeddah, Saudi Arabia.

Mohammed M. S. Jan is a Professor and Consultant of Pediatric Neurology and Clinical Neurophysiology, Department of Pediatrics, Faculty of Medicine, King Abdulaziz University, Jeddah, Kingdom of Saudi Arabia 